\title{
Comparison of the efficacy and safety of topical diltiazem and nitroglycerine for pain relief during transrectal ultrasound guided biopsy of the prostate
}

\author{
Tarun Jindal, Soumendra Nath Mandal, Satyadip Mukherjee, Dilip Karmakar
}

Department of Urology, Calcutta National Medical College, Kolkata, India

\section{ABSTRACT}

Introduction and Objective: Transrectal ultrasound biopsy of prostate is a painful procedure. The introduction of the rectal probe is one of the major contributors to the pain associated with this procedure. Drugs that relax the anal sphincter should theoretically decrease this pain. This study was done to compare the efficacy and safety of two topical medications that relax the anal sphincter, diltiazem and nitroglycerine, in decreasing the pain associated with transrectal ultrasound guided prostate biopsy.

Materials and Methods: 66 patients who were to undergo their first prostate biopsy were randomized to receive either $2 \mathrm{~mL}$ of $2 \%$ topical diltiazem or $2 \mathrm{~mL}$ of $0.2 \%$ topical nitroglycerine or placebo 20 minutes before prostate biopsy. All patients also received $15 \mathrm{~mL}$ of intrarectal lignocaine. A 10-point visual analogue score was used to record the pain immediately after the insertion of the probe, during biopsy and at the end of the procedure.

Results: The pain scores due to probe insertion, during biopsy and at the end of the procedure in patients who received topical diltiazem or nitroglycerine were significantly lower compared to the placebo group $(\mathrm{p}<0.001)$. There were no significant differences in the pain scores between the patients receiving diltiazem compared to those receiving nitroglycerine. Higher incidence of headache and fall in blood pressure was noted in patients who received nitroglycerine compared to those receiving diltiazem.

Conclusion: Topical diltiazem and nitroglycerine are equally effective in reducing the pain associated with transrectal prostatic biopsy. Diltiazem is safer compared to nitroglycerine.

\section{ARTICLE INFO}

\section{Key words:}

Prostate; biopsy; analgesia; lignocaine; diltiazem; nitroglycerin

Int Braz J Urol. 2012; 38: 405-10

Submitted for publication: January 16, 2012

Accepted after revision: May 25, 2012

\section{INTRODUCTION}

Transrectal ultrasound guided biopsy (TRUS-Bx) of the prostate is an established method for the diagnosis of prostatic cancer. The procedure is most commonly performed on an out-patient basis. It is an invasive procedure and is associated with pain thus requiring some form of analgesia $(1,2)$. The pain associated with the procedure has two main causes, first the insertion of the transducer of the ultrasound into the rectum and second the pain due to insertion of the biopsy needle into the prostate $(3,4)$. Numerous methods and agents have been tried in the past to decrease this pain. These can range from topical agents, oral agents, inhalational agents, injections, etc. Topical, intrarectal application of lignocaine is a commonly used modality for this procedure as it anaesthetises the 
rectal mucosa and the prostatic nerves. Periprostatic nerve block (PPNB) with lignocaine infiltration is now being promoted as the standard form of anaesthesia for this procedure. However, periprostatic injection of lignocaine which is given bilaterally to cause nerve block may itself be associated with significant pain and can make the whole procedure uncomfortable for the patient (5). PPNB is ineffective in decreasing the pain associated with the insertion of the transducer of the ultrasound into the rectum. It has been found in various randomized trials that the pain of insertion of probe is actually the most painful part of this procedure $(6,7)$. Relaxing the anal sphincter may help reduce this pain. Theoretically, combining a drug which provides analgesia (e.g. topical lignocaine) with a drug that relaxes the anal sphincter can provide optimum pain control during TRUS-Bx of the prostate. Diltiazem and nitroglycerine have been used topically to decrease sphincter tone in patients with anal fissures $(8,9)$. Thus, these drugs may help decrease the pain of TRUS-Bx of the prostate. We, in this study, evaluated and compared the efficacy and safety of the topical application of diltiazem with nitroglycerine in controlling the pain associated with different stages of the prostatic biopsy.

\section{MATERIALS AND METHODS}

The study was conducted from December 2010 to August 2011. Ethical clearance was obtained from the institutional ethical committee. In all, 66 patients, who were to undergo their first prostate biopsy, were enrolled in the study. These patients either had an elevated prostate specific antigen (PSA) level or/and abnormal digital rectal examination. Each of the participants provided informed and written consent for the study. Exclusion criteria included history of previous transrectal prostate biopsy, chronic prostatitis, prostatodynia, chronic pelvic pain, bleeding diathesis, anticoagulation therapy, anorectal conditions like haemorrhoids, anal fissure, anal stenosis, allergy to lignocaine, diltiazem or nitroglycerine, neurological conditions, recent use of phosphodiasterase- 5 inhibitors, recent use of narcotics, analgesics or antiplatelet drugs, systolic blood pressure of less than $100 \mathrm{~mm} \mathrm{Hg}$ and severe hepatic, cardiac or renal disease. Antibiotic, in the form of oral ciprofloxacin $500 \mathrm{mg}$ twice daily, was started from the day before the procedure and was continued until the fifth postprocedural day. Cleansing enema was given in the morning of the biopsy.

The patients were randomized by the help of a computer program that generated random numbers in three groups. The patients' serial number decided the type of analgesia received i.e. intrarectal administration of either $2 \mathrm{~mL}$ of placebo (group 1) or $2 \mathrm{~mL}$ of $2 \%$ diltiazem gel (group 2) or $2 \mathrm{~mL}$ of $0.2 \%$ nitroglycerine gel (group 3). All patients received $15 \mathrm{~mL}$ of topical lignocaine gel intrarectally. The gels were applied by another operator (S.N.M.). The gels were applied 20 minutes before the biopsy. First, placebo or diltiazem or nitroglycerine was administered following which $15 \mathrm{~mL}$ of lignocaine gel was administered. The patients did not know about the medication they had received.

All biopsies were performed by a single operator (T.J.) who was blinded regarding the type of medication received by the patients. The biopsies were taken in the left lateral decubitus position using an 18-G, $26 \mathrm{~cm}$ long, tru-cut biopsy needle driven by a biopsy gun. A $7 \mathrm{MHz}$ ultrasound probe was used for guiding the prostate biopsies (Shimatzu, SDU-450 XL). In all cases, 12 core biopsy samples were taken in a schematic manner. The pain score using the standard tenpoint visual analogue scale was done, scored 0 meaning no pain, 1-3 meaning mild, 4-6 moderate, 7-9 severe and 10 meaning unbearable pain. The score was done during the insertion of the probe, during the biopsy per se and at the end of the procedure (to determine the overall acceptability of the procedure). This simultaneous assessment of the pain score was done to avoid recall bias. The vitals of the patients were recorded and they were observed for any complications during and after the study (for 72 hours).

The statistical analysis was done using SPSS Statistical data editor (version 17). Due to the non-parametric nature of the data, median values were calculated. The Mann Whitney test and ANOVA were used to calculate the statistical 
significance in the study groups. A p value of less than 0.05 was considered to be significant.

\section{RESULTS}

The median age, volume of the prostate, PSA levels and time taken during biopsy were similar in all the groups (Table-1).

During the insertion of the probe, the patients who received either diltiazem or nitroglycerine with lignocaine reported significantly less pain scores compared to those who received placebo with lignocaine $(p<0.001)$. The pain scores at the time of biopsy and at the end of procedure too were significantly lower in the patients who received diltiazem or nitroglycerine with lignocaine compared to those receiving placebo and lignocaine $(p<0.001)$. There were no significant differences between the pain scores at the time of insertion of probe, during the biopsy or at the end of the procedure, between the patients receiving diltiazem with lignocaine when compared to those receiving nitroglycerine with lignocaine (Table-2).

Two of the twenty two patients (9\%) who received nitroglycerine reported headache within the first hour following biopsy. The blood pressure of these patients reduced to a systolic pressure of less than $90 \mathrm{~mm}$ of $\mathrm{Hg}$. The patients were managed by bed rest, limb elevation and fluid infusion. There were no such complications in patients who received diltiazem or placebo. Complications like hematuria, hematospermia, mild fever and dysuria were noted in 9 patients out of the total study population (13\%).

Table 1 - Characteristics of the patients included in the study.

\begin{tabular}{lcccc}
\hline Variable & $\begin{array}{c}\text { Placebo and lignocaine } \\
\text { (group 1) }\end{array}$ & $\begin{array}{c}\text { Diltiazem and lignocaine } \\
\text { (group 2) }\end{array}$ & $\begin{array}{c}\text { Nitroglycerine and } \\
\text { lignocaine (group 3) }\end{array}$ & $\begin{array}{c}\text { p value } \\
\text { (ANOVA) }\end{array}$ \\
\hline Number of patients & 22 & 22 & 22 & - \\
$\begin{array}{l}\text { Median Age in years (range) } \\
\text { Median volume of the prostate in } \\
\mathrm{mL} \text { (range) }\end{array}$ & $61(55-78)$ & $64(54-74)$ & $62(50-74)$ & 0.58 \\
$\begin{array}{l}\text { Median PSA (ng/mL) level (range) } \\
\text { Time (seconds) taken for biopsy } \\
\text { (range) }\end{array}$ & $11(4.2-21)$ & $12.6(4-22)$ & $64(50-96)$ & 0.82 \\
\hline
\end{tabular}

Table 2 - Pain scores in the three groups during transrectal biopsy of the prostate.

\begin{tabular}{lcccccc}
\hline Variable & $\begin{array}{c}\text { Placebo and ligno- } \\
\text { caine (group 1) }\end{array}$ & $\begin{array}{c}\text { Diltiazem and } \\
\text { lignocaine(group 2) }\end{array}$ & $\begin{array}{c}\text { Nitroglycerine and } \\
\text { lignocaine (group 3) }\end{array}$ & p1 & p2 & p3 \\
\hline $\begin{array}{l}\text { Median VAS score during probe } \\
\text { insertion (range) }\end{array}$ & $5(3-7)$ & $2(1-4)$ & $2(1-4)$ & $<0.001$ & $<0.001$ & 0.35 \\
$\begin{array}{l}\text { Median VAS score during biopsy } \\
\text { per se (range) }\end{array}$ & $5(4-7)$ & $3(1-4)$ & $3(1-4)$ & $<0.001<0.001$ & 0.13 \\
$\begin{array}{l}\text { Median VAS score at the end of } \\
\text { the procedure (range) }\end{array}$ & $5(4-8)$ & $3(1-4)$ & $2(1-4)$ & $<0.001$ & $<0.001$ & 0.29 \\
\hline
\end{tabular}

p calculated by Mann Whitney test. p1: (group 1 v/s group 2); p2 (group 1 v/s group 3); p3 (group 2 v/s group 3). 


\section{DISCUSSION}

Prostate cancer is the most common malignancy in aging men in the Western world. Prostate biopsy is the gold standard exam to identify the patients harbouring the malignancy. With the increasing use of screening for prostatic cancer with the help of digital rectal examination and serum PSA levels, more and more patients are being subjected to prostate biopsy which is most commonly performed under ultrasound guidance using a rectal transducer. TRUS guided prostatic biopsy is an invasive procedure associated with pain and thus requires analgesia/anaesthesia in some form $(1,2)$. The analgesia can be provided by topical, oral, inhalational or injectable agents. Topically applied local analgesics are often used to alleviate this pain as they can be easily administered. Lignocaine, following topic intrarectal application, diffuses into the periprostatic tissue through the rectal wall and blocks the periprostatic nerves which carry the pain sensation. It has been reported in most studies to reduce the pain associated with the TRUS biopsy by more than 50\% (10). Prilocaine and lignocaine mixture has also been used and has been shown to have good results (4). Controversy exists regarding the efficacy of non-steroid anti- inflammatory agents in reducing the pain of biopsy. Oral agents like rofecoxib have not been found to be effective while on the other hand, diclofenac suppositories, one hour before the biopsy have been shown to reduce the pain of biopsy $(11,12)$. Sedation with agents like entonox, midazolam, meperidine, propofol etc. have also been tried but they need strict monitoring as they may risk the patient to cardiopulmonary depression (13-15). Soloway et al., in the year 2000, introduced another method of blockage of the periprostatic nerves with the help of lignocaine infiltration known as PPNB (16). Numerous trials have been conducted which have found PPNB to significantly reduce the pain of prostatic biopsy but few trials have shown that lignocaine gel is as effective as PPNB while a couple of other trials have shown that PPNB is not effective in pain control (17-19). This is probably related to the technique of the operator and the pain threshold of the study population (6). PPNB has also been reported to increase the pain of pros- tatic biopsy as it requires intrarectal injections. Pudendal nerve block has also been tried, albeit occasionally, with good success, either alone or in combination with PPNB.

Pain during prostate biopsy has two components, one due to the insertion of probe (due to the stretching of the anal sphincter) and another due to the biopsy per se. Luscombe et al. found that the pain of insertion of the probe was equally bad or even worse than the pain of biopsy in 27\% of the patients (7). Raber et al. too confirmed this finding and showed that 15\% of men had pain scores of 6 at the time of probe insertion which is significantly high (20). This component of pain is not taken care of by either topical application or infiltration of lignocaine $(6,21)$. Thus, combining pharmaceutical agents that can cause periprostatic nerve block e.g. lignocaine and those which can relax the anal sphincter can reduce the pain associated with prostatic biopsy.

Diltiazem and nitroglycerine have been topically used in the treatment of anal fissures. They relax the anal sphincter, decrease the pain and promote healing of the fissure $(8,9)$. They are commonly used drugs for this indication and are easily available. The notion that this action of these drugs can be of use during the prostate biopsy led to their evaluation in the present study. We used lignocaine gel which can block the periprostatic nerves and thus decrease the pain of needle insertion and nitroglycerine/diltiazem which relax the anal sphincter thus decreasing the pain due to insertion of the probe. Though there are a few studies available which have used nitroglycerine, ours is the first study that evaluates the efficacy and safety of diltiazem and also compares it with nitroglycerine $(6,22)$. Our study also addresses the issue of recall bias which has been often quoted as an issue in the previous studies as pain scores were assessed at each step of the procedure.

Our study found that the pain at the time of insertion of the rectal probe is significantly reduced by application of either diltiazem or nitroglycerine gel along with lignocaine. Median pain scores reduced from 5 (moderate, according to the VAS grading) in the placebo arm to 2 (mild, according to the VAS grading) in the diltiazem or nitroglycerine arm $(p<0.001)$. The pain at the time of biopsy per se was 
also reduced in our study in patients who had an application of diltiazem or nitroglycerine gel compared to the placebo arm $(p<0.001)$. The reason for this is that at the time of biopsy, the operator has to position the probe either at apex, middle or base of the prostate. This probe manoeuvring places the sphincter on stretch and causes pain. Diltiazem and nitroglycerine decrease this component and thus decrease the pain associated with the biopsy. The patients who had diltiazem or nitroglycerine application reported significantly less pain scores at the end of the procedure.

Our study found that two patients who received nitroglycerine reported headache and their systolic blood pressure fell to values less than 90 $\mathrm{mm}$ of $\mathrm{Hg}$. On the other hand, patients who received diltiazem did not have any such side effects. Thus, in our study, diltiazem appears to be safer compared to nitroglycerine, though no conclusive statistical inference can be drawn on this aspect.

\section{CONCLUSIONS}

Our study proves that topical diltiazem and nitroglycerine are better than placebo in reducing the pain associated with the prostate biopsy. Both these drugs are equally effective in reducing the pain. Diltiazem appears to be safer as compared to nitroglycerine due to absence of significant side effects and may be preferred.

\section{CONFLICT OF INTEREST}

None declared.

\section{REFERENCES}

1. Clements R, Aideyan OU, Griffiths GJ, Peeling WB: Side effects and patient acceptability of transrectal biopsy of the prostate. Clin Radiol. 1993; 47: 125-6.

2. Irani J, Fournier F, Bon D, Gremmo E, Doré B, Aubert J: Patient tolerance of transrectal ultrasound-guided biopsy of the prostate. Br J Urol. 1997; 79: 608-10.

3. Autorino R, De Sio M, Di Lorenzo G, Damiano R, Perdonà S, Cindolo $\mathrm{L}$, et al.: How to decrease pain during transrectal ultrasound guided prostate biopsy: a look at the literature. J Urol. 2005; 174: 2091-7.
4. Raber M, Scattoni V, Roscigno M, Dehò F, Briganti A, Salonia A, et al.: Topical prilocaine-lidocaine cream combined with peripheral nerve block improves pain control in prostatic biopsy: results from a prospective randomized trial. Eur Urol. 2008; 53: 967-73.

5. Ashley RA, Inman BA, Routh JC, Krambeck AE, Siddiqui SA, Mynderse LA, et al.: Preventing pain during office biopsy of the prostate: a single center, prospective, double-blind, 3-arm, parallel group, randomized clinical trial. Cancer. 2007; 110: 1708-14.

6. Rochester MA, LE Monnier K, Brewster SF: A double-blind, randomized, controlled trial of topical glyceryl trinitrate for transrectal ultrasound guided prostate biopsy. J Urol. 2005; 173: 418-20.

7. Luscombe CJ, Cooke PW: Pain during prostate biopsy. Lancet. 2004; 363: 1840-1.

8. Lund JN, Scholefield JH: A randomised, prospective, doubleblind, placebo-controlled trial of glyceryl trinitrate ointment in treatment of anal fissure. Lancet. 1997; 349: 11-4. Erratum in: Lancet. 1997; 349: 656.

9. Kocher HM, Steward M, Leather AJ, Cullen PT: Randomized clinical trial assessing the side-effects of glyceryl trinitrate and diltiazem hydrochloride in the treatment of chronic anal fissure. Br J Surg. 2002; 89: 413-7.

10. Issa MM, Bux S, Chun T, Petros JA, Labadia AJ, Anastasia K, et al.: A randomized prospective trial of intrarectal lidocaine for pain control during transrectal prostate biopsy: the Emory University experience. J Urol. 2000; 164: 397-9.

11. Moinzadeh A, Mourtzinos A, Triaca V, Hamawy KJ: A randomized double-blind prospective study evaluating patient tolerance of transrectal ultrasound-guided biopsy of the prostate using prebiopsy rofecoxib. Urology. 2003; 62: 1054-7.

12. Haq A, Patel HR, Habib MR, Donaldson PJ, Parry JR: Diclofenac suppository analgesia for transrectal ultrasound guided biopsies of the prostate: a double-blind, randomized controlled trial. J Urol. 2004; 171: 1489-91.

13. Masood J, Shah N, Lane T, Andrews H, Simpson P, Barua JM: Nitrous oxide (Entonox) inhalation and tolerance of transrectal ultrasound guided prostate biopsy: a doubleblind randomized controlled study. J Urol. 2002; 168: 11620; discussion 120.

14. Tobias-Machado M, Verotti MJ, Aragao AJ, Rodrigues AO, Borrelli M, Wroclawski ER: Prospective randomized controlled trial comparing three different ways of anesthesia in transrectal ultrasound-guided prostate biopsy. Int Braz J Urol. 2006; 32: 172-9; discussion 179-80.

15. Peters JL, Thompson AC, McNicholas TA, Hines JE, Hanbury DC, Boustead GB: Increased patient satisfaction from transrectal ultrasonography and biopsy under sedation. BJU Int. 2001; 87: 827-30.

16. Soloway MS, Obek C: Periprostatic local anesthesia before ultrasound guided prostate biopsy. J Urol. 2000; 163: 172-3. 
17. Chang SS, Alberts G, Wells N, Smith JA Jr, Cookson MS: Intrarectal lidocaine during transrectal prostate biopsy: results of a prospective double-blind randomized trial. J Urol. 2001; 166: 2178-80.

18. Wu CL, Carter HB, Naqibuddin M, Fleisher LA: Effect of local anesthetics on patient recovery after transrectal biopsy. Urology. 2001; 57: 925-9.

19. Walsh K, O'Brien T, Salemmi A, Popert R: A randomised trial of periprostatic local anaesthetic for transrectal biopsy. Prostate Cancer Prostatic Dis. 2003; 6: 242-4.

20. Raber M, Scattoni V, Roscigno M, Rigatti P, Montorsi F: Perianal and intrarectal anaesthesia for transrectal biopsy of the prostate: a prospective randomized study comparing lidocaine-prilocaine cream and placebo. BJU Int. 2005; 96: 1264-7.
21. Giannarini G, Autorino R, Valent F, Mogorovich A, Manassero F, De Maria M, et al.: Combination of perianal-intrarectal lidocaine-prilocaine cream and periprostatic nerve block for pain control during transrectal ultrasound guided prostate biopsy: a randomized, controlled trial. J Urol. 2009; 181: 585-91; discussion 591-3.

22. McCabe JE, Hanchanale VS, Philip J, Javle PM: A randomized controlled trial of topical glyceryl trinitrate before transrectal ultrasonography-guided biopsy of the prostate. BJU Int. 2007; 100: 536-8; discussion 538-9.

\section{Correspondence address} Dr. Tarun Jindal Department of Urology,

Calcutta National Medical College,

Kolkata, India

Telephone: +096 7 444-4929

E-mail: drtarunjindal@gmail.com 